\title{
Pleasant and unpleasant violations of expectancies ${ }^{1}$
}

PATRICIA L. SHAPIRO, ${ }^{2}$ Pennsylvania State University, University Park, Pa. 16802, and JEROME E. SINGER, ${ }^{3}$ Educational Testing Service, Princeton, N.J. 08540

Two experiments varied importance, confirmation, and solution to test whether or not disconfirmation of expectancies is unpleasant. In Experiment 1, two pleasant solutions were tasted. For one solution, disconfirmation was unpleasant in the importance condition, pleasant in the unimportance condition. In Experiment 2, two unpleasant solutions were tasted; no significant differences were demonstrated. Interpretations are given for sensory, dissonance, and need for variety factors. Reasons for solution differences are discussed.

One derivation from Festinger's (1957) cognitive dissonance theory is that disconfirmed expectancies will be unpleasant; expecting $\mathbf{A}$ is dissonant with the nonoccurrence of $A$, or with occurrences that preclude A. Festinger has described dissonance as a state of "psychological discomfort." This discomfort may generalize, resulting in an individual's judging his experiences during a period of dissonance as less pleasant than he otherwise would. Carlsmith \& Aronson (1963) demonstrated an expectancy-disconfirmation-unpleasantness effect by asking Ss to judge solution tastes. The $\mathrm{E}$ employed hand signals to create an expectancy of either a quinine or sugar solution. On critical trials, E reversed signals, disconfirming $S$ 's expectancies. Both solutions were rated less pleasant on these trials than on trials when $S$ tasted what he expected to taste. Sampson \& Sibley (1965) partially replicated Carlsmith and Aronson's design, but confirmed their results for only the sugar solution. Carlsmith and Aronson do not assert that disconfirmed expectancies will always be unpleasant, and many instances of pleasure following disconfirmation can be cited (e.g., humor is often an expectancy violation accompanied by pleasant affect). Importance was high in Carlsmith and Aronson's study, and a high level of task importance or ego-involvement may be necessary for disconfirmation to be unpleasant. In the present experiments, degree of task importance was varied on the assumption that situations low in importance could bore Ss, making disconfirmation a pleasant surprise. Disconfirmation was also studied with solutions differing less widely in pleasantness than quinine and sugar.

\section{EXPERIMENT}

Procedure

A 2 by 2 by 2 factorial design varied importance (important, I vs unimportant, UI), confirmation (expectancy confirmed, EC vs expectancy disconfirmed, ED), and solution (cherry, $\mathrm{CH}$ vs lemon, $\mathrm{L}$ ). The $\mathrm{Ss}$ were 48 female employees of Educational Testing Service (ages 18-50), met individually by $\mathrm{E}$ and informed they would be judging the pleasantness of solutions. The UI Ss were told only that the task involved taste perception, and I Ss were told that the ability to discriminate among solutions is related to the ability to understand others, to predict behavior, and to being successful in dealing with others. Prior to the 10-trial test series, Ss tasted the "standard concentration" of each solution three times. They were told to rate each of the test solutions in relation to its own standard, i.e., cherry for cherry solutions, lemon for lemon solutions. Each standard was rated at 10 , and Ss were told to rate test solutions more pleasant than their standards above 10, and those less pleasant below 10 . Only one concentration of each solution was used. The $\mathrm{CH}$ Ss tasted lemonade on Trials 1-7 and 9-10, and cherry soda on the eighth trial. The $\mathbf{L}$ Ss tasted lemonade only on Trial 8 . These solutions were used to determine whether or not disconfirmed expectancies would affect $S$ 's taste perception of solutions less widely different in pleasantness than quinine and sugar. Pretests demonstrated that the solutions were discriminable yet approximately equal in pleasantness. Expectancies were based on cup color. In the standardization trials and test series, cherry was always in a cup of one color and lemon in a cup of a different color. To eliminate color and odor cues, the tops of the cups were covered, and the solutions were dyed to match, and sipped through opaque straws. On Trial 8 , EC Ss received the solution in the same color cup previously used for that solution. The ED Ss' expectancies were disconfirmed by their tasting cherry in the color cup usually used for lemon or vice versa.

$$
\text { Results }
$$

Group means are presented in Table 1. A significant I by EC interaction was found for $\mathbf{L}$ Ss, indicating that task importance affected $S$ 's reaction to disconfirmed expectancies. On the critical trial, I-EC Ss rated the lemonade more pleasant than I-ED Ss. This replicates Carlsmith and Aronson's finding that disconfirmation of important expectancies is unpleasant. Also on the critical trial, UI-ED Ss rated lemonade as more pleasant than did UI-EC Ss, indicating that disconfirmation can be pleasant. Neither main effect was significant: $E C$ vs $E D, F<1, d f=1 / 20$; $I$ vs $U I, F<1$, df $=1 / 20$. Similar analyses for the $\mathrm{CH}$ data indicated no significant differences; all $\mathrm{F}$ ratios were $<1$.

\section{EXPERIMENT 2}

\section{Procedure}

The Ss were 64 male and female undergraduates at The Pennsylvania State University. The design was similar to that of Experiment 1 except for the following modifications. Quinine (Q) and ascorbic acid (A) were used to determine how Ss would react to two unpleasant solutions. The importance manipulation was modified slightly to include the notion that the ability to form accurate expectancies was indicative of S's ability in many areas. The relation between establishment of expectancies and the ability to deal with others was also strengthened to increase task importance. Prior to the 10-trial test series, half of the Ss tasted quinine three times and the others tasted ascorbic acid. The solution tasted was designated the standard solution and assigned a rating of -10 . The Ss were instructed to rate all test solutions in relation to the single standard. A rating of $>-10$ indicated that the solution was more pleasant than the standard, and a rating of $<-10$ indicated that it was less pleasant. All ascorbic acid solutions were made of equal parts of Cecon (ascorbic acid suspended in propylene glycol) and Reallemon. The quinine consisted of $.325 \mathrm{~g}$ of quinine sulphate per quart of water. Pretest data demonstrated that the solutions were

Table 1

Mean Ratings of Solutions

\begin{tabular}{|c|c|c|c|c|c|c|c|c|}
\hline & \multicolumn{4}{|c|}{ Experiment 1} & \multicolumn{4}{|c|}{ Experiment 2} \\
\hline & \multicolumn{2}{|c|}{$\begin{array}{c}\text { Lemonade } \\
\text { Solutions }\end{array}$} & \multicolumn{2}{|c|}{$\begin{array}{l}\text { Cherry } \\
\text { Solutions }\end{array}$} & \multicolumn{2}{|c|}{$\begin{array}{l}\text { Quinine } \\
\text { Solutions }\end{array}$} & \multicolumn{2}{|c|}{$\begin{array}{c}\text { Ascorbic Acid } \\
\text { Solutions }\end{array}$} \\
\hline & $\mathrm{EC}$ & $\mathrm{ED}$ & $\mathrm{EC}$ & ED & $\mathrm{EC}$ & ED & $\mathrm{EC}$ & ED \\
\hline I & 8.83 & 5.00 & 12.50 & 13.00 & -14.9 & -9.3 & -12.9 & -10.5 \\
\hline$\underline{\mathrm{UI}}$ & 3.83 & 8.50 & 10.17 & 11.00 & -10.5 & -9.0 & -7.6 & -9.8 \\
\hline
\end{tabular}


discriminable in taste, but not in color or odor, and approximately equal in unpleasantness. Due to their unpleasantness, Ss were given only $.2 \mathrm{cc}$ per trial. On all trials except the critical eighth trial, quinine was given to ED Ss in a spoon of one color and ascorbic acid in a spoon of a distinctly different color. On Trial 8 for ED Ss, $Q$ was given in the color spoon usually used for $A$, and vice versa. Quinine was used as the standard for Q Ss and ascorbic acid for $\mathrm{A}$ Ss. Each $\mathrm{S}$ tasted the same solution as his standard on Trials $3,4,6,8$, and 10 , and the other solution on the remaining trials.

\section{EXPERIMENT 2}

\section{Results}

Group means are listed in Table 1. The hypothesis that the pleasantness of a disconfirmed expectancy depends upon task importance was not supported. Analyses of variance performed on these data did not demonstrate any significant differences.

\section{DISCUSSION}

The results of Experiments 1 and 2 together with those of the earlier experiments cited indicate that expectancy disconfirmation is unpleasant only under fairly restricted conditions. First, the situation must be important and ego-involving, and secondly, it seems in retrospect that either (1) the disconfirmed expectancy must be affectively neutral, or (2) the disconfirmation must be quite unpleasant.

Results for the $L$ condition of Experiment 1 will be considered first. One interpretation of the results of the $I$ manipulation is that disconfirmed expectancies arouse dissonance only if the task is seen as important. The only case in which solutions were rated as less pleasant on the ED trials was one that was highly ego-involving. Other studies have shown that dissonance reduction does not occur unless $S$ is involved in the task (e.g., Deutsch, Krauss, \& Rosenau, 1962; Zimbardo, 1960). The $\mathrm{L}$ results also fit Fiske \& Maddi's (1961) need for variety theory. These authors view unexpectedness, reward, and punishment as sources of affect, and argue that a moderate degree of unexpectedness is most likely to be experienced as pleasant when reward and punishment are minimized. Both were minimized in the UI condition of Experiment 1, but were heavily involved in Carlsmith and Aronson's study since incorrect anticipations meant that $S$ lost money and was a poor judge of others. In the I condition of Experiment 1, reward and punishment were present in that disconfirmation per se could be unpleasant for $S$ in an important situation. Disconfirmation could lead $S$ to doubt his understanding of the instructions and his adequacy of performance on earlier trials, while confirmation could be rewarding by increasing $S$ 's confidence.

The present failure to replicate Carlsmith and Aronson's results for three of the solutions may be accounted for by extending Sampson and Sibley's explanation for their failure to replicate the quinine results. They argue that their disconfirmation procedure was less unpleasant than Carlsmith and Aronson's since their Ss' pay was independent of correctness, and further, that this smaller increment of unpleasantness was perhaps not sufficient to produce a jnd relative to the already unpleasant quinine solution. However, the unpleasantness of disconfirmation was sufficient to be noticed relative to the pleasant solution and was reflected in its ratings. This same type of argument may be applied to the results for the $\mathrm{CH}, \mathrm{A}$, and $Q$ solutions in our experiments for two reasons. First, our disconfirmation procedure was more similar to Sampson and Sibley's than Carlsmith and Aronson's, since no money was involved. Second, our unpleasant solutions were probably more unpleasant and the cherry soda more pleasant than the comparable solutions used in the earlier studies. This is relevant because as the solution tasted is made increasingly pleasant or unpleasant, disconfirmation must be made increasingly unpleasant or S's ratings will not reflect it, and our disconfirmation procedure was less unpleasant than Carlsmith and Aronson's. As to the solutions in Experiment 2 being more unpleasant than in the other studies, our quinine was approximately four times more concentrated than the solutions used in the earlier experiments, and the ascorbic acid was equally unpleasant. Also, the cherry soda was probably more pleasant for Ss than the pleasant solutions of either of the earlier experiments, or the lemonade in Experiment 1. Our Ss in all conditions rated the cherry soda on the critical trial as more pleasant than its standard despite the identity of all solutions, suggesting that they found the soda very pleasant. Also, Ss in all conditions rated the lemonade on the critical trial as less pleasant than its standard (since lemonade was tasted after seven $\mathrm{CH}$ trials, it perhaps tasted somewhat bitter). In both of the earlier experiments, the pleasant solutions were sometimes rated more and sometimes less pleasant than the standards. If cherry soda were more pleasant for $S s$ than the other solutions, it may be that it was too pleasant for its ratings to be affected by a small amount of unexpectedness produced by disconfirmation.

One other explanation for the results of Experiments 1 and 2 is possible. The solutions tasted in each study were matched for pleasantness so a disconfirmed expectancy meant only that the Ss tasted solutions they did not expect to taste, and not solutions differing markedly in pleasantness from their expectations. In the earlier experiments, both sorts of expectancies were disconfirmed. Since Ss who expect pleasant solutions may hold what they taste in their mouths longer than those who expect unpleasant solutions, the results of these earlier experiments may possibly be explained solely on a sensory basis. The $Q$ solutions may have been judged as more unpleasant on ED trials than on EC trials simply because Ss tasted it more fully on ED trials. Similarly, sweet solutions may have been rated as less pleasant on ED than on EC trials because ED Ss, expecting an unpleasant taste swallowed the solutions more quickly than EC Ss and did not fully taste their sweetness. Significant results in studies where the sensory explanation was possible together with weak results in Experiments 1 and 2 , where this alternative was ruled out, makes it reasonable to argue that the earlier results are handled better by the sensory explanation than the dissonance explanation.

In summary, the results of the various experiments dealing with disconfirmed expectancies may be interpreted in two ways. Carlsmith and Aronson's dissonance explanation may be correct, but less generally correct than they argued. It appears that disconfirmations only of important expectations, of moderate affective tone, are unpleasant. Alternatively, the dissonance explanation may be unnecessary as the results are accountable for by the sensory explanation.

\section{REFERENCES}

CARLSMITH, J. M., \& ARONSON, E. Some hedonic consequences of the confirmation and disconfirmation of expectancies. Journal of Abnormal \& Social Psychology, 1963, 66, 151-156.

DEUTSCH, M., KRAUSS, R. M., \& ROSENAU, $\mathrm{N}$. Dissonance or defensiveness? Journal of Personality, 1962, 30, 16-38.

FESTINGER, L. A theory of cognitive dissonance. Evanston: Row, Peterson, 1957.

FISKE, D. W., \& MADDI, S. R. Functions of varied experience. Homewood: Dorsey, 1961. SAMPSON, E. E., \& SIBLEY, L. B. A further examination of the confirmation or nonconfirmation of expectancies and desires. Journal of Personality \& Social Psychology, $1965,2,133-137$.

ZIMBARDO, P. G. Involvement and communication discrepancy as determinants of opinion conformity. Journal of Abnormal \& Social Psychology, 1960, 60, 86-94. NOTES

1. Supported by Grant MH-07515 from NIMH to the second author.

2. Now at the University of Hawaii, Honolulu, Hawaii 96822.

3. Data collected 1956-1966 while on leave of absence from the Pennsylvania State University. Now at the State University of New York at Stony Brook, Stony Brook, N.Y. 11790. 